\title{
Institutionalizing the Kyoto Climate Accord
}

\author{
by Bharat H. Desai*
}

\section{Introduction}

One year after the Kyoto Climate Protocol opened for signature (on 16 March 1998) at UN headquarters, 87 States out of 176 parties to the Framework Convention on Climate Change (FCCC) ${ }^{1}$ had put their signatures to it. Now, any State wishing to join the Kyoto Protocol, ${ }^{2}$ can only acceed ${ }^{3}$ to it. The Protocol will need at least 55 ratifications to come into force, which must include developed countries whose emissions account for at least 55 per cent of all global greenhouse gas (GHG) emissions. ${ }^{4}$ Does this convey a positive signal that governments are taking evidence of climate change seriously? The list of signatory states does include Japan, the European Union (15 member States) and the United States, which contribute to the bulk of the GHG emissions. However, in the absence of any major GHG emitter state ratifying the Kyoto accord, its fate still hangs in the balance.

\section{Quantified Threshold}

The advent of the FCCC, with the objective of stabilization of GHG concentrations in the atmosphere, has been a remarkable development in terms of efforts at laying down international legal restraints upon States' environmental behaviour. The Kyoto accord has become a first concrete step, though not the best one, in laying down a threshold limit for quantified reduction of select GHG agents. The climate change issue has been shrouded in a lot of scientific uncertainty. In fact, the Conference of Parties (COP) of the FCCC is expected to take cognizance of the scientific evidence made available from time to time by the Intergovernmental Panel on Climate Change (IPCC). ${ }^{5}$ In its Second Assessment

* Director, Centre for Environmental Law, World Wide Fund for Nature-India and Senior Assistant Professor, International Legal Studies Division(SIS), Jawaharlal Nehru University, New Delhi. Currently a Humboldt Fellow at Institute of International Law, University of Bonn, Germany. This does not necessarily reflect the views of WWF-India.
Report the IPCC has already held that 'balance of evidence now suggests that there is a discernible human influence on climate.'

The FCCC is comprised of a fragile consensus on soft obligations couched in a hard legal instrument. This has necessitated flexibility as regards in-built law-making within the Convention. It being primarily a framework Convention, the Conference of Parties (COP), the supreme decision-making body of the FCCC, had to negotiate a separate protocol to lay down targets and timetables for reduction of emissions of GHGs. This came about after difficult and arduous negotiations on the basis of the 'Berlin Mandate.' ${ }^{6}$ The industrialized States, having primary ${ }^{7}$ responsibility in the matter, agreed on 'quantified emission limitation and reduction'(QELAR) objectives at COP $3^{8}$ held in the Japanese city of Kyoto. The Climate Protocol adopted ${ }^{9}$ at Kyoto became unique as it required only the industrialized states to reduce GHG emissions in the first place. The invoking of the criteria of differentiated ${ }^{10}$ responsibility was much more real for the climate change issue, as compared to the earlier ozone regime under the 1987 Montreal Protocol ${ }^{11}$ where both industrialized and developing countries assumed obligations, ${ }^{12}$ with certain grace periods for the latter.

The Kyoto deal took shape amidst reports of continued deterioration in the state of the global environment ${ }^{13}$ since UNCED (1992), a downward trend in the ratio of Overseas Development Assistance to GNP, ${ }^{14}$ as well as reluctance of the industrialized countries at the 19th Special Session of the General Assembly (Rio plus 5) to make available additional funding to developing countries. As a result, the developing countries have put up resistance to any efforts to require them also to join in the QELAR. The QELAR commitments agreed upon comprise just 5.2 per cent reduction in collective emissions by 39 industrialized (Annex I) ${ }^{15}$ countries, as compared to the European Union's willingness

0378-777X/99/\$12.00 (C) 1999 IOS Press 
for a 15 per cent reduction. ${ }^{16}$ A representative of Greenpeace, however, dubbed the deal as a tragedy and a farce. The fact, however, remained that some of the industrialized countries found the economic and political costs of emission reduction difficult in the short term. This led to inclusion of devices to cushion their pain and, if possible, to pass on the burden to others. The recent COP $4^{17}$ in November 1998 at Buenos Aires could not succeed in clearing much of the haze surrounding the workability of the Kyoto deal in view of the foot-dragging by some States. As such, the Buenos Aires Action Plan ${ }^{18}$ laid down a work programme to be undertaken to resolve outstanding issues under the Protocol by the COP 6 in 2000. The Buenos Aires meeting brought into sharp focus North-South differences in tackling the challenge of climate change. In fact, States having primary responsiblity were, according to the Worldwatch Institute, concerned more with "shifting the burden of climate problem on to others."19

\section{Primary Responsibility}

The Kyoto deal, in effect, was a step towards the acceptance of the principle of primary responsibility of the industrialized countries for global climate change. Many elements of the Protocol were controversial and left undecided, to be fleshed out later. Though the Kyoto Protocol imposes legally binding targets for emissions reduction, the process is conditional upon the exercise of political will as well as the willingness to bear economic costs, on the part of the industrialized States. Interestingly, a modest level of 5.2 per cent combined quantified emission limitation and reduction (QELAR) commitments agreed to in Kyoto for the 39 Annex I States has been cushioned with a 'grace period' till 2008. The three 'flexibility mechanisms, 20 incorporated in the Kyoto accord, which are essentially designed to minimize the 'pain' of meeting the economic costs involved in reaching the specified targets, have also not been without controversy. The vague and uncertain formulations in the Protocol will, it is felt, 'assist' the developed countries in warding off any potential and economic political fall out resulting from giving effect to QELAR commitments domestically. In an international environmental convention involving more than 175 parties with sharp polarisation and hard positions, such a deal was not unexpected.

The task before the delegates at Buenos Aires, who were representing nearly 170 countries, was to finalize the operational details of the Kyoto Protocol. The agenda of the Buenos Aires conference included discussion on the implementation of the Kyoto Protocol, consideration of various national positions relating to the emission of GHGs, discussion on issues relating to the transfer of technology and the efforts to flesh out the three 'flexibility mechanisms.' The laying down of the 'rules of the game' generated a lot of heat and kept the negotiators busy for a fortnight in hard bargaining. The politics and economics of global warming, as compared to ominous scientific evidence of human-induced climate change, which played a crucial role in shaping the Kyoto Proto- col, continued to dominate the proceedings at Buenos Aires. The centerpiece of these negotiations, as usual, were the issues of equity and ethics.

\section{Kyoto Mechanisms}

The most contentious issues on the Buenos Aires agenda were the three 'Kyoto mechanisms', i.e. the international emissions trading regime, the clean development mechanism and the joint implementation mechanism. These mechanisms are aimed at helping the developed countries in reducing the cost of reaching their combined 5.2 per cent emissions reduction targets by the period 2008-2012.

The Kyoto accord envisioned a new currency of GHG permits, which could be encashed from a buyer on the open market. Under an international 'emissions trading regime,' the industrialized countries may transfer or acquire, among themselves, any excess reduction of GHGs beyond their respective targeted QELAR. This mechanism will allow industrialized countries to buy and sell emissions credits among themselves. It is expected that the price to be quoted for buying of 'hot air' (emissions credits) will be based on the needs of buyer and seller. This arrangement is suited to the interests of those industrialized countries who have the ability to buy 'hot air' and do not want to incur immediate political cost domestically. An important issue in this trading will be the question of fixing ceilings on the purchase of such 'hot air.' In the absence of a ceiling, a country can, through 'market magic,' either substantially reduce or even get away from meeting its QELAR target simply because it can afford to pay. The Kyoto trading system, it is argued, "will fail, because it is a shell game" 21 , especially since most of these permits are likely to be sold by countries such as Russia and the Ukraine whose economies are down at this time and therefore their emissions in 2008-2012 will be far below the Kyoto targets.

The 'joint implementation' (JI) mechanism aims at providing credits for investments made in GHG reduction projects - only in other developed countries. In this case too, the ability of a country to invest can be used to offload some of its burden of QELAR at home. This intra-industrialized countries mechanism may be beneficial if appropriate reporting rules, comparable methodologies as well as project guidelines are established by the COP.

The 'clean development mechanism' (CDM) is designed to 'assist' the industrialized countries who are willing to finance emissions-avoiding projects and also fulfill the objective of sustainable development in developing countries. CDM and JI will, in turn, provide credits for financing emissions avoiding projects in developing countries. The CDM has been regarded as a 'surprise tool' of Kyoto. It emanated from the idea of a Green Development Fund, mooted by Brazil, at a late stage in negotiations preceding the Kyoto meeting. In Kyoto, the idea took an entirely different shape as compared to the original purpose to fund it from pollution fines paid by 
the parties in 'non-compliance.' The industrialized countries succeeded in stalling efforts to designate this scheme as a fund, which would give an impression that they have an obligation to pay for it. Clearly the aim was not to make it a climate fund in future to assist the developing countries. This mechanism also does not take into account 'historical emissions' of industrialized countries. As a result, it has turned out to be a vague form of JI with developing (non-Annex I) countries. Through this 'extra-territorial implementation' the industrialized countries can offset a part of their QELAR at a considerably cheaper cost, with an added bonus of having 'assisted' non-Annex I countries. G-77 countries accepted CDM at Kyoto in the belief that new and additional funding as well as transfer of technology will flow through this mechanism. The CDM, in order to be workable and acceptable to all countries, will need to be transparent, equitable and accountable.

A wide range of views exists on these 'flexibility' mechanisms. For instance, some have dubbed CDM as a pure commodification of the atmosphere at the altar of market forces. Others consider it a useful tool for initiating the process of realization of the commitments of the industrialized countries. The US, fearing that the clean development mechanism would receive too much attention to the disadvantage of the emissions trading regime, insisted that the two mechanisms move towards operational status on parallel tracks. The EU opposed the US demand for a free market approach to global greenhouse gases emission cuts, including unrestricted international trade pollution permits. The flexibility mechanisms were hotly debated at Buenos Aires but no final decisions were taken.

The surprise at Buenos Aires was the introduction of the concept of 'voluntary commitments' (VCs) for emissions reduction by Argentina and Kazakhstan. China, India and other developing countries opposed this. In practical terms, it amounts to drawing the developing countries too into the process of QELAR, which they have been opposing tooth and nail since the Berlin Mandate process started. Noting that the Kyoto Protocol does not include any emission abatement commitments for the developing countries, they felt that this would lead to a split in their stand against VCs. The developing countries argued that the developed countries must first act on what has been agreed upon and refrain from trying to foreclose the developing countries' right to develop. ${ }^{22}$ The crux of the debate was drawing the distinction between 'luxury' and 'survival' emissions, as it was argued by India, that without the implementation of agreed targets, voluntary reduction would be meaningless. In the coming years, as the climate regime gradually unfolds, the issue of developing countries joining the QELAR commitments will be quite contentious. These countries have been arguing, on the basis of 'common but differentiated' responsibility, that it is the industrialized countries who are primarily responsible for global warming and, therefore, they must have a primary role in emissions reduction. ${ }^{23}$ The developing countries have all along consistently argued that they do not want to pay for the sins (GHG emissions) they never committed. Besides, even in the absence of voluntary commitments, some of the leading developing countries such as India, China, Brazil and Mexico are understood to have already in place several measures domestically, which will have the effect of cutting down of GHG emissions. $^{24}$

\section{Subterfudges}

There have been subtle hints as regards the developing countries undertaking emissions reductions under the euphemism of 'meaningful participation.' It comprises the view that India, China and Brazil, in particular, make commitments for emissions reduction. This would amount to the involvement of developing countries in the QELAR process from the back door. It is argued that voluntary commitments will unlikely remain so 'voluntary' in actual practice. This demand is coupled with the implicit threat of witholding of the US ratification of the Kyoto Protocol. Though the United States, which accounts for about a quarter of the world"'s emissions of carbon dioxide, signed the Kyoto Protocol (on 12 November 1998) during the COP 4, there is no indication that it is in any hurry to submit it to the Senate for ratification. The non-participation of the US, the largest single emitter of GHGs, will effectively cripple the Kyoto Protocol. If that happens, it will jeopardize the delicately crafted agreement on minimal GHG reduction, upturning the Kyoto applecart.

The Buenos Aires COP has laid down a two-year Plan of Action. The Action Plan establishes deadlines for finalizing the outstanding details of the Kyoto Protocol so that the agreement will be fully operational, when it may enter into force sometime after the year 2000. It also fixes deadlines for finalizing the flexibility mechanisms by the year 2000 (by COP 6), with "priority given to the clean development mechanism." ${ }^{25}$ The Buenos Aires conference outlined the process for overcoming the difficulties relating to the transfer of environmentally sound technologies from the developed to the developing countries. The developing countries received commitments, in principle, from the developed countries for finance $^{26}$ and technology transfer.

\section{Tenth Session of Subsidiary Bodies}

At the recently concluded tenth sessions of the Subsidiary Body for Scientific and Technological Advice (SBSTA) as well as the Subsidiary Body for Implementation (SBI), from 31 May-11 June in Bonn, emphasis was placed on meeting the goals of the Buenos Aires Plan of Action. As per the schedule, the three Kyoto mechanisms were considered ${ }^{27}$ by the parties, where different groupings of States made statements about their positions. It appears that the process of 'fleshing out' is still active and parties have been proposing various proposals which could best reflect their interests. The core issue, however, will be to what extent the three mechanisms help in attaining the basic objective of the FCCC. 
Will the end product really reflect desire, on the part of developed country parties, to give effect to their primary responsibilty, taking into account both historical and current emissions of GHGs? Various escape devices and subterfudges have come to be thrown into the process, which can only further immediate narrow national interests of the parties rather than common interest for attainment of long-term stabilization of GHGs.

The issues concerning guidelines for the preparation of national communications as well as methodological issues were also considered at the Bonn meeting. The SBSTA Chair's conclusions ${ }^{28}$ on the guidelines advised the SBI to set up a two-year trial period starting in early 2000 , to assess FCCC reporting guidelines on annual inventories which could be revised at COP7. The draft decision proposed by SBSTA recommended that the COP adopt the guidelines on inventories, to be used by Annex I Parties for reporting inventories due by 15 April each year (starting 2000). The guidelines also include the common reporting format (CRF) for the purpose.

Several States have adopted careful positions so that controversial issues do not derail the process. A draft decision presented by the G-77/China ${ }^{29}$ has insisted on excluding such issues from the agenda of COP 5. Japan accepted most of the G-77/China suggestions, except on timing for the high-level segment. This might have aimed at any effort for introducing issues such voluntary commitments (as done at COP 4) or so-called 'meaningful participation' for developing countries. In accordance with the Buenos Aires Action Plan, since COP 6 would be decisive for institutionalizing the Kyoto Protocol, COP 5 would mainly serve at resolving various pending issues, including the mechanisms.

At a joint meeting of SBSTA/SBI several issues such as the AIJ pilot phase, procedures and mechanisms concerning compliance under the Protocol, as well as three 'flexibility mechanisms' were considered. On several issues the States have, partly or fully, unfolded their positions. In the run up to the COP 5 meeting, scheduled to be held in Bonn in October/November 1999, the FCCC Secretariat will have much work put on it in the coming days for reports requested by the subsidiary bodies. In fact the process of institutionalizing scope and content of contentious issues such as the three 'flexibility mechanisms' and compliance would prove to be an acid test for the parties to the FCCC. It remains to be seen as to how the negotiators accomodate different positions on linkage between compliance with Kyoto obligations and participation in the Kyoto mechanisms. Another crucial issue would be avoiding concepts and devices put forward by States which have the potential ultimately to undermine the "Kyoto Protocol's already limited environmental effectiveness." 30 It is feared that some of these subterfudges would lead to no action by the Protocol's Annex B parties to comply with their commitments. The divergence of positions between the European Union and the Umbrella Group ( comprising of non-EU Annex countries) on issues such as prescribing a 'ceiling' as well as ensuring 'supplemental,' as compared to open ended, use of the Kyoto mechanisms have already revealed the fissures, which have the potential to throw the process into disarray.

\section{Conclusion}

With just seven ratifications forthcoming (until March 1999), from small island States who hardly, if at all, contribute to GHG emissions, the fragile Kyoto climate applecart will be faced with an uphill task of narrowing the gap between sharply polarised divisions among the parties. The scientists and environmentalists have already warned that the Kyoto targets are far below what is actually needed to tackle the problem of global warming. In the coming months, the sincerity of industrialized countries will be on test as regards making a genuine beginning on putting into effect meagre Kyoto targets. Unless the big GHG emitters take a concrete initiative in the matter, the COP 5, may not have much to offer on the future of the Kyoto accord. The process of institutionalizing the Protocol will have a decisive effect on its future. Moreover, it appears, that the prospects for coming into force as well as the effectiveness of the Kyoto Protocol are to be conditioned more by the political and economic factors than scientific warnings or legal expectations. Ironically, as the experience of the ozone issue shows, it is generally some 'trigger event' which forces States to implement international regulatory measures in earnest.

\section{Notes}

1 United Nations Framework Convention on Climate Change was adopted by the Intergovernmental Negotiating Committee (INC) at its last session on 9 May 1992, at UN headquarters in New York. The Convention was opened for signature in June 1992 during the Rio Earth Summit. It was signed in Rio by the Heads of State and other senior representatives from 154 States (and the EU). The FCCC entered into force on 21 March 1994 and as on 7 October 1998 it was ratified by 176 States; for the text see FCCC Secretariat, Convention on Climate Change (Bonn: FCCC Sec., 1999), pp. 2-30. Also see ILM, vol. 31, 1992, p. 849 (hereinafter "the FCCC").

2 The FCCC being a framework Convention, needed a subsequent protocol (as per Article 17) for achieving its long-term objective of preventing "dangerous anthropogenic interference with the climate system". As such, the first Conference of Parties (COP) met in Berlin (1995) launched a new round of talks on strengthening developed country commitments. It resulted in consensus decision at COP 3 (1/CO.3) in Kyoto (December 1997) to adopt a Protocol under which (only) the industrialized countries will reduce their combined greenhouse gas (GHG) emissions by at least 5 per cent at 1990 levels by the period 2008-2012; for text of the Protocol see, FCCC Secretariat, The Kyoto Protocol to the Convention on Climate Change (Bonn: FCCC Sec., 1998), pp. 3-28 (hereinafter "the Kyoto Protocol").

3 The Kyoto Protocol was open for signature from 16 March 1998 to 15 March 1999 at the UN headquarters. As per Article 24, the Protocol opened for accession from the day after the date on which it was closed for signature (i.e. 15 March 1999). As on 16 March 1999, the Protocol was signed by 84 States and ratified by 7 States.

A State can be said to have acceded to a treaty when it formally accepts provisions of a treaty (not signed by it) already signed by other States. This may take place either before or after the treaty has entered into force. The material point in deciding the issue of accession is the date on which the treaty is closed for signature. In fact, accession is only one of the modes of expressing consent to be bound by a treaty. In practical terms it, generally, amounts to admixture of both signature and ratification, conveyed after the closer of date of signature, through an instrument of accession deposited with the designated depository; see Articles 2(1)(b), 11, 15 and 16 of the Vienna Convention on the Law of the Treaties, adopted on 22 May 1969; for the text see UN Doc.A/CONF.39/27, 23 May 1969. Also see ILM, vol. 8,1969 , p. 679

4 The Kyoto Protocol, Article 25.

5 For instance, the 1995 Second Assessment Report of the Intergovernmental Panel on Climate Change (IPCC) could distinguish human induced climate change from natural climate variability. Inspite of uncertainties regarding some of the key 
factors, the IPCC concluded that the "balance of evidence now suggests that there is a discernible human influence on climate." The scientific panel has in fact predicted that global temperatures would continue to increase beyond 2100 , even if concentrations of GHGs were "stabilised"; see IPCC Working Group I, Summary for Policy-Makers: The Science of Climate Change (Second Assessment Report, 1995), pre-publication copy. Also see Bharat Desai, "Humans Endanger Earth's Climate", The Times of India (New Delhi), 10 July 1996, edit page.

6 The First Conference of Parties meeting of the FCCC, Decision 5/CP.1; see UN Doc. FCCC/CP/1995/7/Add.1, 6 June 1995, p. 4.

7 The scheme of the FCCC has been premised upon an explicit understanding that since the "largest share of historical and current global emissions of greenhouse gases has originated in developed countries", these countries "should take the lead in combating climate change and the adverse effects thereof"; see the FCCC, Preamble and Article 3.

8 Report of the Conference of Parties on Its Third Session, Kyoto, 1-11 December 1997; see UN Doc.FCCC/CP/1997/7, 18 March 1998.

9 Decision 1/CP.3 (and Annex) of 11 December 1997; see Action Taken by the Conference of the Parties at Its Third Session, UN Doc. FCCC/CP/1997/7/Add.1, 18 March 1998

10 The criteria of 'common but differentiated responsibility' has been carved out during negotiations on the FCCC, which underscores that same responsibility can not be attributed to developed (industrialized) and developing States which are at different stages of economic development. Though the climate change issue has been regarded as a 'common concern of humankind,' States parties to the FCCC will have differentiated responsibility. As such the developed countries were requied to take the 'lead;' it was conceded that the share of global emissions originating in developing countries will in fact "grow to meet their social and development needs;" ibid.

11 The Protocol on Substances that Deplete the Ozone Layer, Montreal, 16 September 1987; see ILM, vol. 26, 1987 , p. 1550 . Also see EPL, vol. 17, 1987, p. 256

12 For details on the phase-out schedule under the Montreal Protocol see Bharat Desai, "Global Accords and Quest for a New International Ecological Order: From Law of Indifference to Common Concern," Business \& the Contemporary World, vol. 9, no. 3, 1997,

pp. 545-572 at 553. Also see the Phase-out schedule for Article 5 countries, Ozone Action Special Supplement no, 4 in Our Planet, vol. 9, no. 2, 1997, p. 16.

13 The Global Environment Outlook report has recently painted a grim scenario of the environmental challenge:

"(F)rom a global perspective the environment has continued to degrade during the past decade, and significant environmental problems remain deeply embedded in the socio-economic fabric of nations in all regions. Progress towards a global sustainable future is just too slow. A sense of urgency is lacking;" see UNEP, Global Environment Outlook (Oxford: OUP, 1997), p. 3.

14 UN, Programme for the Further Implementation of Agenda 21, Adopted by Governments at Earth Summit+5, Special Sesseion $\left(19^{\text {th }}\right)$ of the U.N. General Assembly, 23-28 June 1997, New York (New York: UN, 1997), p. 62

15 The FCCC listed, in Annex I, originally the following countries: Australia, Austria, Belarus, Belgium, Bulgaria, Canada, Denmark, European Economic Community, Estonia, Finland, France, Germany, Greece, Hungary, Iceland, Ireland, Italy, Japan, Latvia, Lithuania, Luxembourg, Netherlands, New Zealand, Norway, Poland, Portugal, Romania, Russian Federation, Spain, Sweden, Switzerland, Turkey, Ukraine, United Kingdom of Great Britain and Northern Ireland, United States of America. Following the decision taken at COP 3 (Decision 4/ CP.3) Annex I was amended to include the following countries: Croatia, Czech Republic, Liechtenstein, Monaco, Slovakia and Slovenia. This amendment entered into force on 13 August 1998; see the FCCC, p. 29

The 5.2 per cent combined quantified emission limitation or reduction commitment (QELAR) agreed upon in the Kyoto Protocol applies to GHGs listed in Annex A for 39 countries listed in Annex B. This excludes Belarus and Turkey, listed in Annex I to the FCCC from QELAR commitments.

16 On the basis of analysis by the European Commission, the EU reached to the conclusion that "a 15 per cent reduction of GHGs was technically and economi- cally feasible, if other industrialized countries undertook comparable efforts;" see Ritt Bjerregaard, "Call for more action," Our Planet, vol. 9, no. 6, 1998, p. 6. 17 Report of the Conference of the Parties on Its Fourth Session, Buenos Aires, 2-14 November 1998; see UN Doc.FCCC/CP/1998/16, 25 January 1999.

18 Decision 1/CP.4 of 14 November 1998; see Action Taken by the Conference of the Parties at Its Fourth Session, UN Doc. FCCC/CP/1998/16/Add.1, 20 January 1999, p. 4.

19 Worldwatch Briefing, "Buenos Aires Climate Negotiations," 18 November 1998, at http://www.worldwatch.org/alerts/981118.ht

20 The Kyoto Protocol's three mechanisms are: (i) Activities implemented jointly by projects for reducing anthropogenic emissions by sources and enhancing removals by sinks of GHGs (Article 6); (ii) clean development mechanism to assist Annex I parties in achieving compliance with their QELAR and assisting non-Annex I parties in achieving sustainable development (Article 12) and (iii) emissions trading between parties in Annex B for the purposes of fulfilling their commitments under Article 3 (Article 17). In the absence of consensus, all three mechanisms were slated for 'fleshed out' by the parties subsequently.

21 David G. Victor, "Kyoto Shell Game," The Washington Post, 20 November 1998.

22 A submission made by Indonesia, on behalf of Group of 77 and China, reaffirmed para 3 of the FCCC Preamble that "the share of global emissions originating in developing countries will grow to meet their social and development needs," It expressed concern that "according to their national communications, most of the developed country Parties will not be able to honou their evidently inadequate commitments of returning to their 1990 levels their anthropogenic emissions of the greenhouse gase as required of them under Article 4.2(b)." Moreover, they also firmly insisted that "any such review [of commitments under Article 4.2(a) and (b)] shall not introduce any new commitments for developing country parties;"' see UN Doc. FCCC/CP/1998 MISC.6, 5 October 1998, p. 10 11.

23 In fact in their submissions, the developed country parties consciously underscore their responsibility. For instance, Australia submitted that: "Annex countries are conscious of their responsibility to take the lead in combating climate change and the

Courtesy: UNEP - "Taking action"

Kyoto Protocol provides the means of demonstrating this leadership role. The strengthening of commitments of Annex I parties under the Protocol is an important step along a longer-term path aimed at achieving the ultimate objective of the Convention;" see UN Doc. FCCC/CP/1998/MISC.6, 5 October 1998, pp. 3-7 at 3.

24 For instance, India is understood to have increased its wind generation capacity from $69 \mathrm{MW}$ to $820 \mathrm{MW}$ from 1992 to 1996 and has potential of 20,000 MW wind generation (total renewable energy potential of about 126,000 MW from wind, micro-hydro, biomass/bioenergy, ocean thermal power, tidal power and sea wave power); see http://www.un.org/esa/agenda21/natlinfo/countr/india/natur.ht In the case of China, renewable energy (including hydro power and biomass) now accounts for 25 per cent of energy use.

25 See COP 4 Decision 7/CP.4 at Doc. FCCC/CP/1998/L.21, 14 November 1998, para 1, p. 2

26 The COP 4 decided that the restructured Global Environment Facility (GEF) shall be an entity entrusted with the operation of the financial mechanism referred to under Article 11 of the FCCC; see Decision 2/CP. 4 and Decision 3/CP.4. Also see Doc. FCCC/CP/1998/L.15, 10 November 1998.

27 See UN Docs. FCCC/SB/1999/4, FCCC/SB/1999/INF.2 and Add.1-3, FCCC/SB/1999/MISC.3 and Add.1, Add.2 and Corr.1 and Add.3.

28 The SBSTA Chair's draft conclusions and a draft decision for the COP guidelines for the preparation of national communications ( UN Doc.FCCC SBSTA/1999/L.5 ) were considered on $10^{\text {th }}$ June 1999.

29 The G-77/China position mainly regarded COP 5 as a technical meeting, as such it did not favour a Committee of the Whole; see Earth Negotiations Bulletin, vol. 12, no. 110, 14 June 1999, p. 21, electronic version at http://www.iisd.ca/linkages/climate/bonn99/.

30 See $i$ bid, p. 38. 